\title{
DESCRIPTION OF THE APPARATUS USED FOR TESTING CURRENT-METERS, AT THE ADMIRALTY WORKS AT TORQUAY FOR EXPERIMENTING ON MODELS OF SHIPS.
}

Bx Mr. Robert gordoN, of Bunmait.

The Current-Meters to bo tested aro towed by a dynamometrical apparatus through still water in a large tank, which gives a parallelsided water-space $278 \mathrm{ft}$. long, $36 \mathrm{ft}$. broad, and for the most part $10 \mathrm{ft}$. deep, though it shallows up at the ends. It is roofed from end to end, the framework of the roof carrying a light railway with a clear space between the rails, which run the entire length of the building at about 20 inches above the normal water-level. In Figs. 1, 2, and 3, Plate 24, is shown the general arrangement of tank and railway.

A stout-framed truck T, Fig. 4, Plate 25, suspended from the axles of two pairs of wheels, runs on the railway, and carries the recording and measuring apparatus. A sheet of paper is wound round a cylinder $R$, carried by the truck; and the cylinder is moved by a band from the hinder axle, so that the circumferential travel of the paper represents, on a reduced scale, the forward motion of the truck. A pen A, actuated by clockwork, marks time on the cylinder as it revolves. $A$ second pen $B$ is moved electrically, and marks indents on the recording paper for every $25 \mathrm{ft}$. run by the truck. A third pen $\mathrm{C}$, moved electrically, can be used for recording the number of revolutions made by the meter under trial, contact being made inside the meter in the method actually arranged for use. A fourth pen D is required for recording the force actually used for towing the object through the water. Generally not more than three or four pens are used at one time for recording: another occasional pen $E$ is sometimes required to show slight quick or slow variations in the rate of speed of the truck and object during the experiment. The 
arrangement of all five pens is shown in Fig. 4, Plate 25, together with the recording cylinder $R$, and the resistance-measurer or dynamometer G. A sixth pen $\mathrm{F}$ is used in ship-model experiments, as well as the pen $\mathrm{C}$, so as to record the indications of two very small and delicate current-meters, which precede the model some distance ahead, and show whether the speed of the model through the watcr differs from the measured speed over the ground, in virtue of any slight current set up by previous experiments. Specimens of the actual records taken are shown full size in Figs. 8 and 9, Plate 27 ; Fig. 8 shows records from the pens $A, B, F$, and $C$; and Fig. 9 from the dynamometrical pen $D$.

The dynamometer consists of a vertical beam G, Fig. 4, hung on a fixed centre $\mathrm{H}$ by a double knife-edge suspension. From its lower end a link $\mathrm{L}$ takes the towing strain of the model; while a knifeodge fixed in the beam $G$, at an equidistant point above the centre $H$, carries one end of the spring $S$, whose extension measures the resistance of the model, the other end being attached to a knifeedge $\mathrm{N}$, fixed in the truck. The uppermost extremity of tho beam is linked at $J$ to the multiplying lever $M$, which moves the resistancerecording pen $D$ on the paper. An extensive collection of springs permits by substitution any resistance to be measured; but the actual strain corresponding with the indications of the recording pen is determined by weights $W$ applied to the end of the horizontal lever $K$ at a point whose distance from the centre $H$ equals that of the towing link $\mathrm{L}$ and the resistance-spring $\mathrm{S}$.

The arrangement for testing the Deacon meter is shown in Fig. 4, Plate 25, where a round bar nearly an inch in diameter carried the meter; but it was found expedient in the rating experiments to substitute for the round bar one of tapering or fish-section, as shown at $P$ in Fig. 4 and to a larger scale in Fig. 5, Plate 26, set with its edges in the direction of the run, as the round bar was observed to cause eddies and a disturbance in the water, likely to interfere with accuracy of record in the instrument when used for high velocities. Some very valuable experiments had previously been made at these Works, bearing on this point, when bodies of globular and other shapes had been towed at various speeds while loosely 
held by a cord. It was found that tho globes wobbled and danced about violently, owing to the eddies formed behind them; but by lengthening out the rear end of each globe to a point, great steadiness ensued, and the objects followed in straight lines. It is proposed to utilise these results in future meters.

The truck is moved by an endless wire-rope coiled in a spiral groove on an accurately turned barrel, which is driven by a small double-cylinder engine, having a heavy and highly-speeded fly-wheel, and a governor of very exact action, of such arrangement that any required steady speed from $40 \mathrm{up}$ to $1000 \mathrm{ft}$. per minute can be assigned by it to the truck.

The governor is complicated with a number of parts formerly useful, but now no longer required; in principle it may be described in general terms as a modification of the Watt governor, but greatly improved. In the ordinary governor the action is due to the position of the balls, which in virtue of their altitude, rising with increase of spced, shut off the steam at the throttle-valve: the reverse happening when they fall lower. In Mr. Froude's governor, illustrated in the diagrams, Figs. 6 and 7, Plate 26, the balls are not allowed to travel outwards beyond a certain angle; beyond this angle the link $L$, acting on the inner end of the stationary lever $V$, against the fulcrum $F$, presses a brake-block $B$ against a disc $D$, which rotates about the same spindle and with the same angular velocity as the governor balls; so that whenever a proper amount of steam is used, and when there is no variation in load, the balls will revolve at their proper angular altitude, and the stationary brake-block will be just in contact with the rotating disc, but exerting no pressure upon it. But should an excess of speed take place, however small in amount, due either to lessened load or to increased steam-pressure, then immediately pressure will exist between block and disc, proportioned to the excess of speed, which pressure will tend towards making tho block accompany the dise in its rotation; but this motion is hindered and kept within narrow limits by the pull of a spring $S$, which keeps the block against a fixed stop so long as the true speed is maintained. The travel of the block away from its stop is a measure of the 
friction between the brake and the disc, or in other words is a measure of the excess of speed.

T'he position of the brake-block governs the extent of opening of the throttle-valve, which is open when the block is close home to its stop, and becomes closed as the block departs from the stop, that is as the excess in speed over that required becomes larger. Tho steam pressure is thus out off immediately there is any excess of speed. The adjustment of the critical speed at which the throttlevalve becomes acted upon is made by adjusting the position of the governor balls $W$ along the arms $A$. Also the centripetal force is given, not by the statical weight of the balls as in the Watt governor, but by springs $\mathrm{C}$, the arms and balls being statically balanced.

This arrangement acts with such accuracy and delicacy that a variation in speed of half a foot per minute is rarely found to occur, even in the fastest runs of the truck. In practice such variations are observed with sufficient accuracy on the "speedle," which is a water column in an open glass-tube fixed near the hauling engine. The head of water in this tube is maintained by a centrifugal pump worked through suitable gearing by the rotating shaft of the engine. A scale placed alongside the tube shows the speed at which the truck is moving at the time when the observations are made. The scale was marked by actual experiment and by subdivision; a height of $3 \frac{1}{2}$ inches of water column measures a variation in speed of $10 \mathrm{ft}$. per minute when running at about $300 \mathrm{ft}$. per minute.

In testing either ship-models or meters, a length of only 150 to $200 \mathrm{ft}$. in the central part of the run of the truck is used, a certain portion being allowed for getting up and lowering down speed at the onds. For certain purposes it has been found desirable to have a longer run; and arrangements are in progress for moving the whole establishment to Haslar, where the new tank will be something like $500 \mathrm{ft}$. long.

In rating the Deacon meters it was not found necessary to have a great number of experiments, each at a different speed; but usually only three speeds were employed, of $1 \mathrm{ft}$., $2 \mathrm{ft}$, and $8 \mathrm{ft}$. per second; 
and a master curve gave all the intermediate speeds. This standard or master curve is one obtained from a series of experiments with meter No. 1, and may be looked upon as perfectly accurate in giving the rate-curve of this meter at the time of trial.

In Fig. 10, Plate 27, are given tho rate-curves of this metcr and of two others, in order to show the method of inferring the rate-curves of the different meters from the master curve shown by the strong line. The abscissæ represent the speed in feet per second, the ordinates the travel of the log through the water for a given number of turns of the screw. The curves are similar curves, those of meters Nos. 10 and 11, shown by the dotted and full fine lines, being inferred by a process of trial and error from the master curve of No. 1 by appropriate alterations in the scales for the ordinates and abscisse. The reasons for this similarity are founded on mathematical considerations not immediately obvious, but which need not be entered upon here.

Any small current in the water of the tank, such as may arise from draughts of air or from the previous experiments, proves quite sufficient to produce very tangible error in the indications of individual experiments. For eliminating such errors in testing tho meters, the plan was at first tried of reversing the meters at the end of each run, and making an experiment in the opposite direction after a sufficient interval of time. But it was found that this method, whilst eliminating the error from fortuitous variation of current, due to draughts or other accidental causes, introduced a fresh error from the fact that there was always a current against tho direction of the run, caused by the water disturbance and by the wind of the truck in the previons run. To avoid this, the practice now is, after each experiment in one direction (say from north to south), to return instantly (from south to north) at the same speed, in order thereby to obliterate as far as possible the effect on the current; then lift the moter out of the water, and travel slowly back from north to south; and then replace the meter to face northwards, and take a new experiment from south to north. The mean of such a pair of experiments, or still better of two pairs, will be very frec from error due to current. 
The foregoing account has been prepared with the kind pormission and aid of Mr. R. Edimund Froude, of the Admiralty Experiment Works, Torquay; and with the help of Mr. J. R. Perrett, who supplied explanations and drawings.

\section{Discussion.}

Mr. GorDon wished to call particular attention to the beautiful governor described in the paper, the action of which was exquisite. It had been designed and modified by the late Mr. Froude, and it was perfectly marvellous to see the accuracy and ease with which any speed from 40 up to $1000 \mathrm{ft}$. a minute could be given by it to the truck. Ho was surprised that it had not been used in ordinary practice. It was very easily constructed. There was a right-andleft-hand screw by which the balls were moved along their arms, outwards or inwards. There were three pulleys on the engine-shaft, and a strap from one or other of these three pulleys gave three rates of speed. The adjustment of the governor balls on their arms gave the means of altering the speed of the truck from 200 to 330 feet per minute; and the rest of the range of speed was got by shifting the strap on the pulleys.

The Presidunt presented the thanks of the meeting to Mr. Gordon for the very interesting paper which he had brought before them. 
TESTING CURRENT-METERS.

Plate 24.

Fig. 2. Trunsverse Section

at middle of Tank.

\section{Testing Tank.}
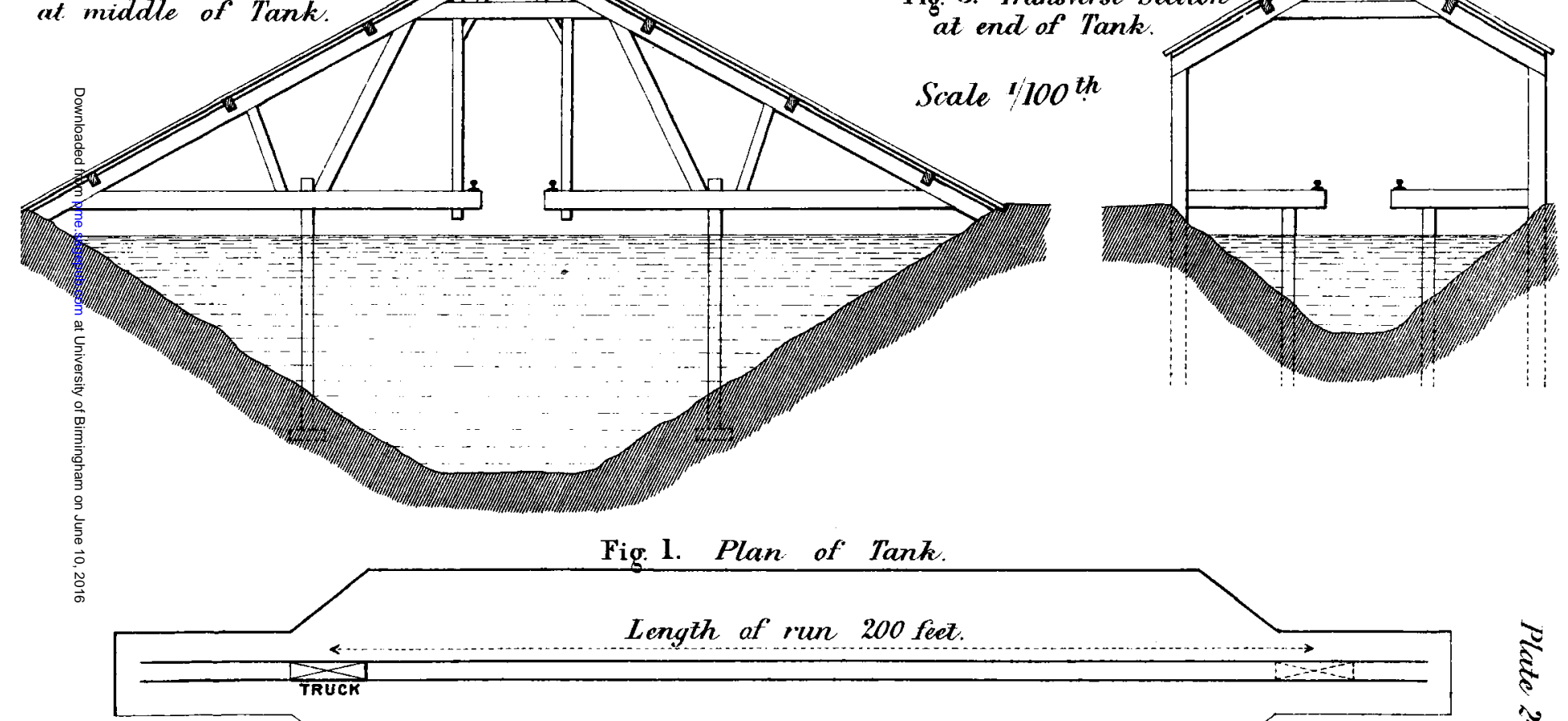

Fig. 1. Plan of Tank.

(Proceedings Inst. M. E. J884)

Scale $1 / 500$ th 
TESTING CURRENT-METERS.

Fig. 4 .

Recording Apparatus.

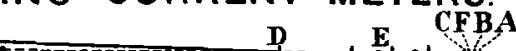

Plate 25.

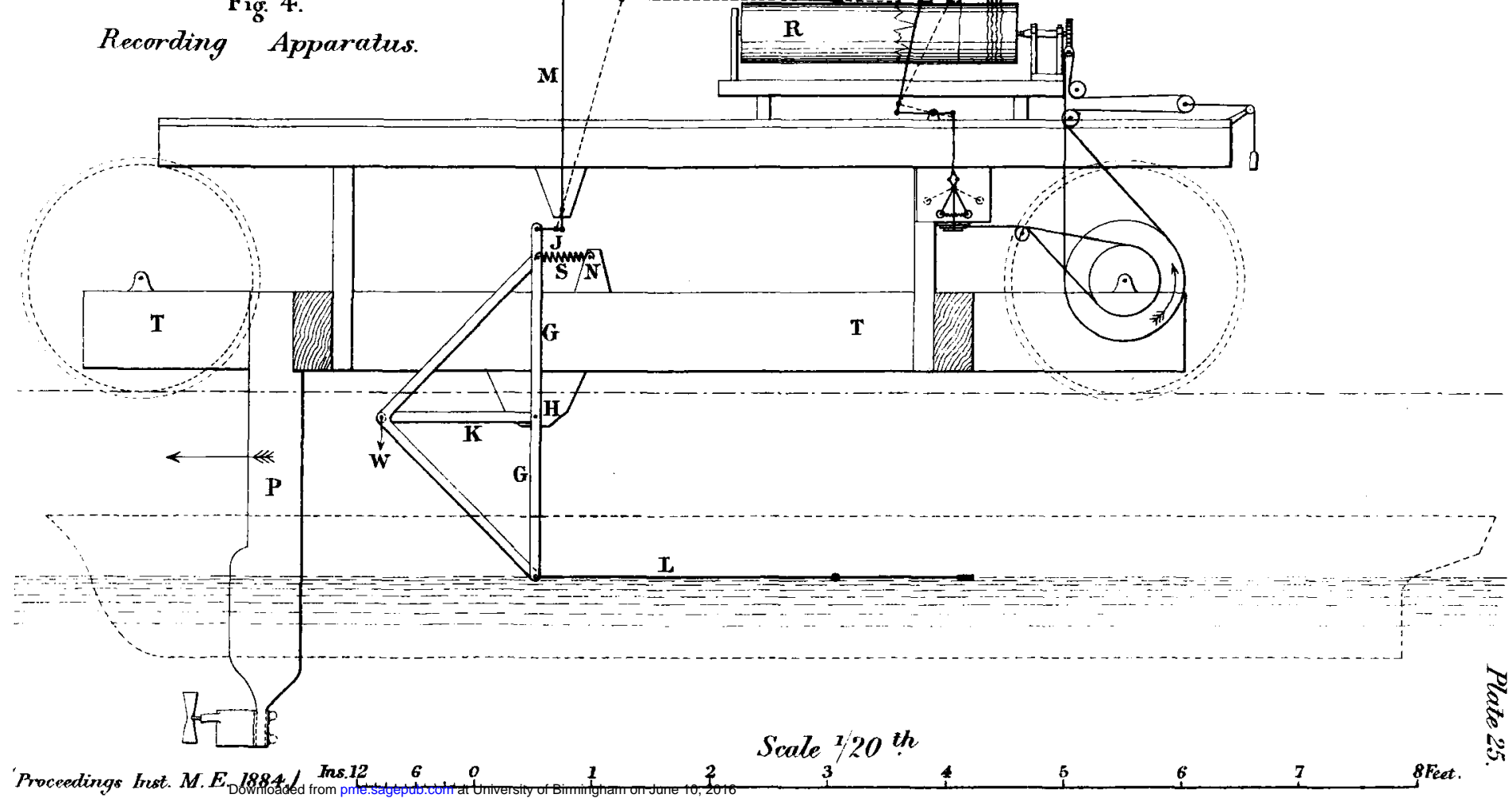




\section{TESTING CURRENT-METERS. Plate 26:}

Fig 5. Meter Carrier.

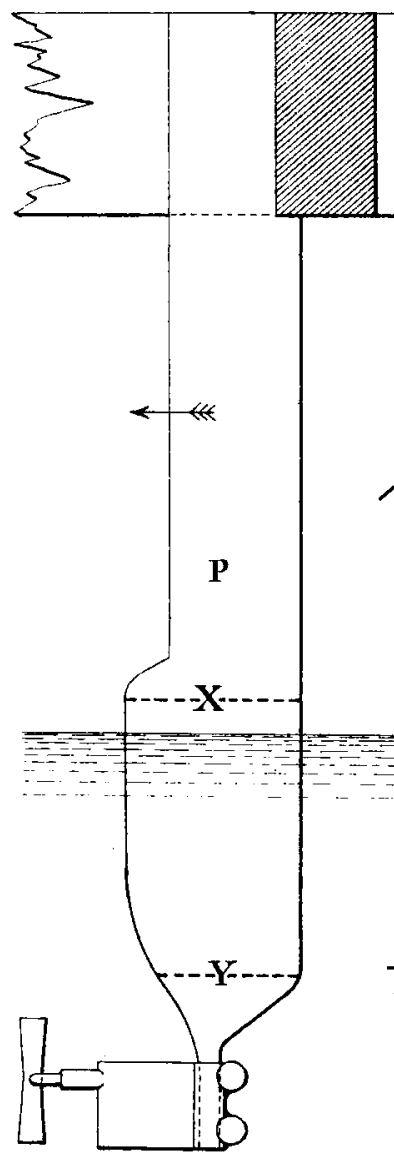

Section at X.
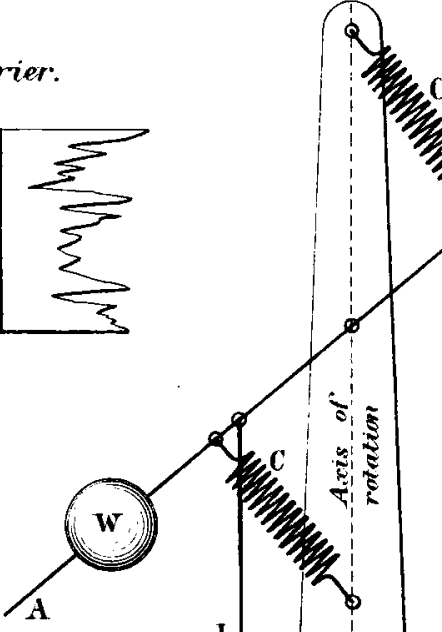

A

$\mathrm{w}^{-}$

Fig: 6.

Elevation

of Governor.
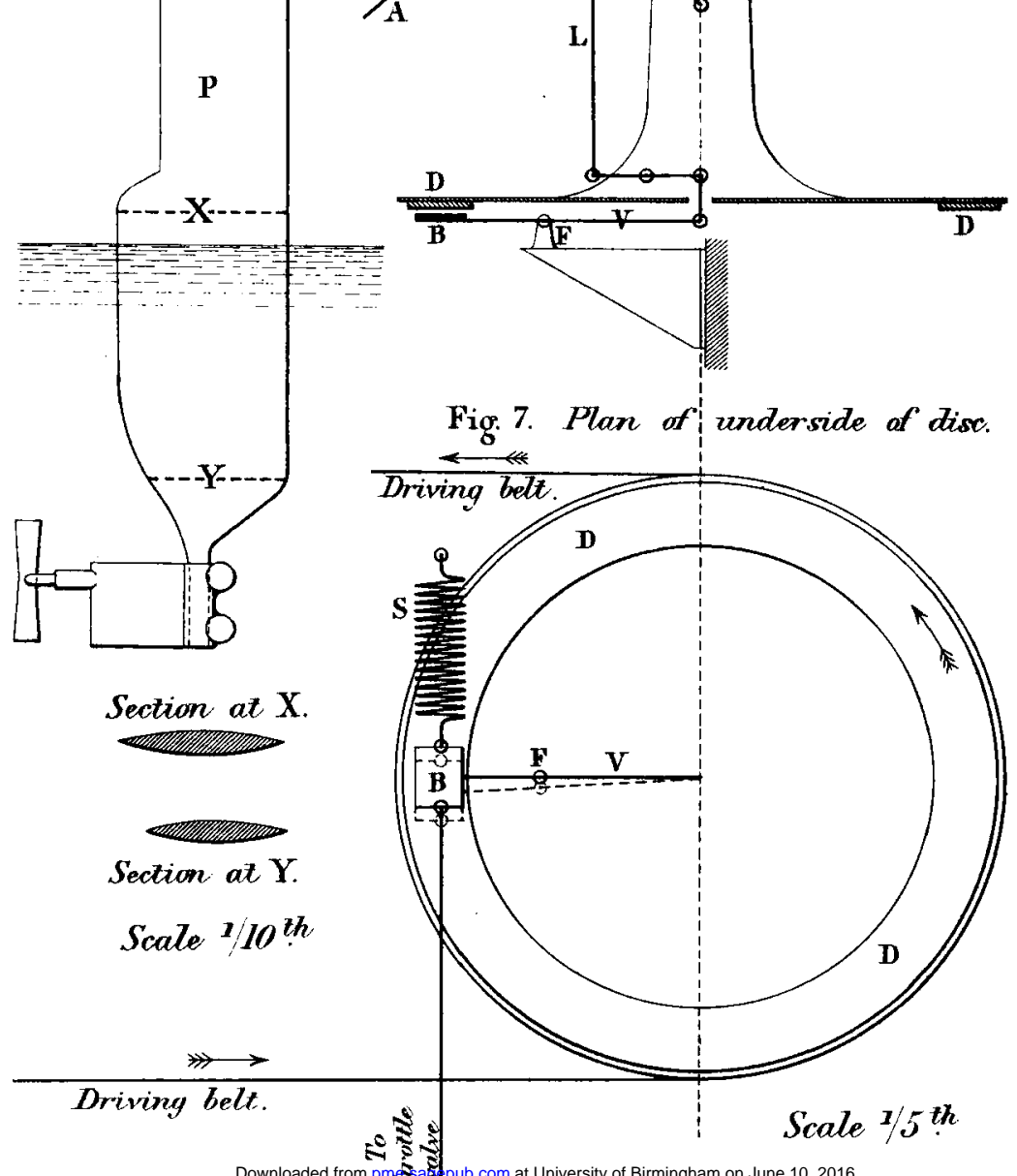
TESTING CURRENT-METERS. Plate 27.

Fig. 8. Records from experiments with small meter. Full size.
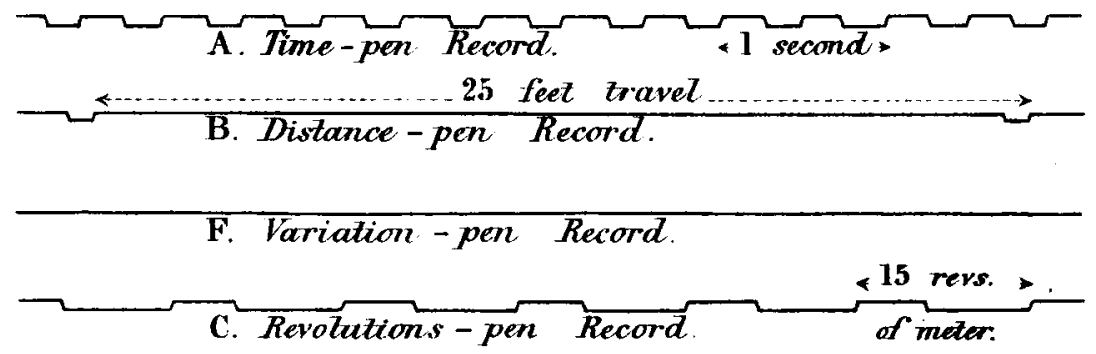

Fig: 9. Dynamometrical-pen Records. Fall sixe.
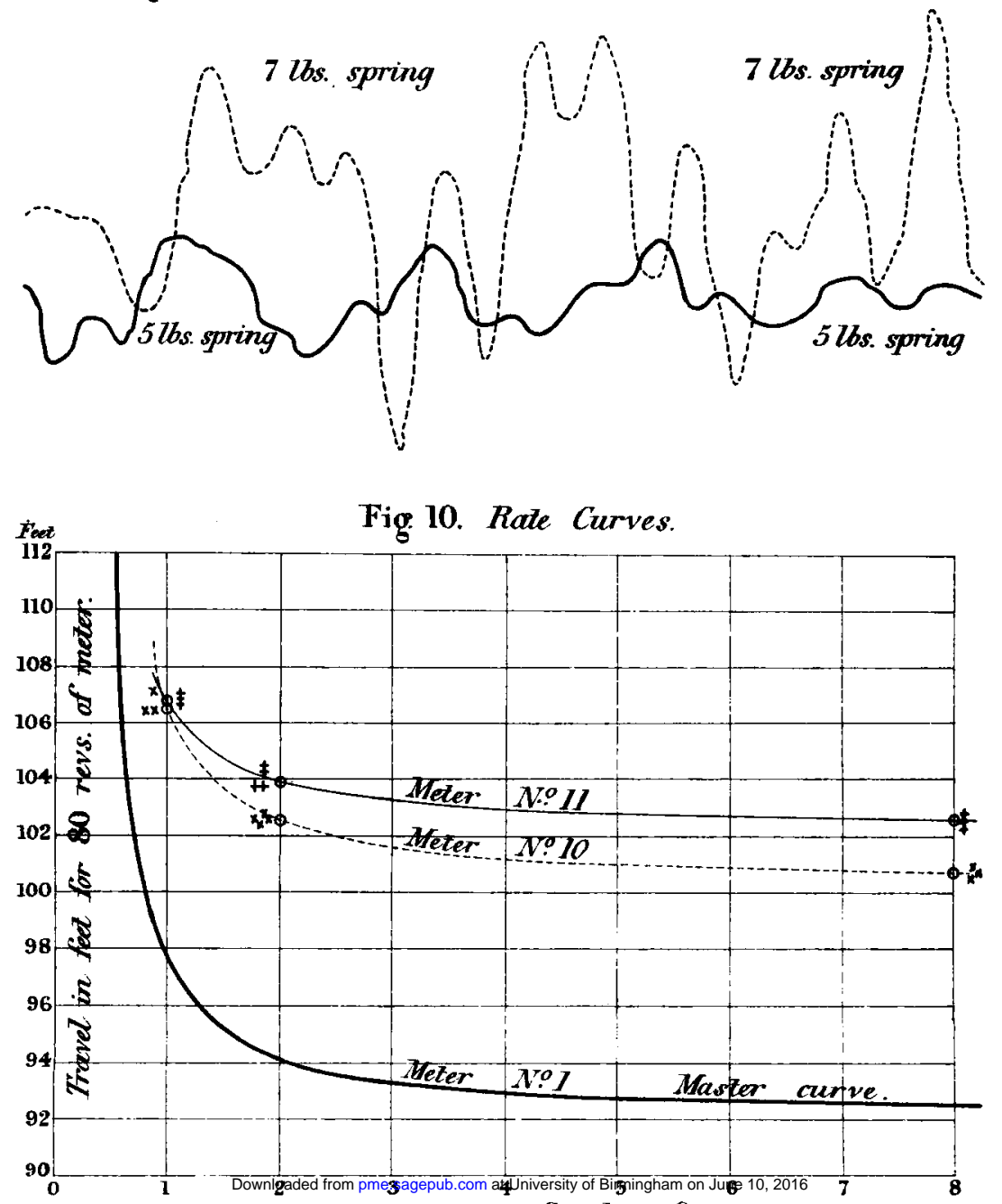

(Proceedings hist. M.E. 1884) Speed in feet per second 